\title{
The Interplay of Pedestrian Navigation, Wayfinding Devices, and Environmental Features in Indoor Settings
}

\author{
Verena Schnitzler* \\ Chair for Cognitive Science \\ ETH Zurich
}

\author{
Ioannis Giannopoulos \\ Institute of Cartography \\ and Geoinformation \\ ETH Zurich
}

\author{
Christoph Hölscher \\ Chair for Cognitive Science \\ ETH Zurich \\ Iva Barisic \\ Chair for Cognitive Science \\ ETH Zurich
}

\begin{abstract}
The focus of this study is on wayfinding in large complex buildings with different wayfinding devices. The interaction of pedestrians of such devices is always also interplay with the surrounding environment and its specific features. Furthermore different wayfinding assistances can elicit different needs for additional information from the environment to make accurate choices at decision points. We aim to shed light on how characteristics of decision points in combination with different wayfinding devices shape wayfinders' visual attention. 60 participants individually looked for three destinations in the same order. They navigated with 1) a printed map, 2) a digital map, or 3) without a map, only using full-coverage numeric signage. To gain first insights fixation frequencies on maps and signage as well as the correct and incorrect route options were recorded with a mobile eyetracker and analyzed for 28 decision points and four decision point categories. The results indicated that starting points play a special role in planning the route ahead. Furthermore points that allow for a floor change lead to a higher attention and information search.
\end{abstract}

Concepts: • Human-centered computing Human computer interaction (HCI); Empirical studies in HCI; Field studies

Keywords: Wayfinding assistance, navigation, spatial cognition, mobile eye tracking, pedestrian navigation

\section{Introduction}

The metaphorical space of a computer becomes usable via graphical user interfaces (GUI), for the physical space maps and signs can fulfill the same function of easing navigation [Schnitzler and Hölscher 2015]. Classic in-car navigation devices give the driver route instructions. There are several approaches to support pedestrians, e.g. with vibro-tactile or auditory interactions but their main navigation devices are still maps -printed or digital - offering a survey perspective on the surrounds [Ishika-

*verena.schnitzler@gess.ethz.ch

Permission to make digital or hard copies of all or part of this work for personal or classroom use is granted without fee provided that copies are not made or distributed for profit or commercial advantage and that copies bear this notice and the full citation on the first page. Copyrights for components of this work owned by others than the author(s) must be honored. Abstracting with credit is permitted. To copy otherwise, or republish, to post on servers or to redistribute to lists, requires prior specific permission and/or a fee. Request permissions from Permissions@acm.org.

ETRA '16, March 14 - 17, 2016, Charleston, SC, USA

Copyright is held by the owner/author(s). Publication rights licensed to ACM.

ACM 978-1-4503-4125-7/16/03 ..\$15.00

DOI: http://dx.doi.org/10.1145/2857491.2857533 wa and Montello 2006; Siegel and White 1975]. Those different presentation modes each have their specific benefits. While navigating we have to constantly update our current location, acquire, store, recall and decode information about our relative location and goal [Downs and Stea 1973]. While route instructions allows drivers to keep their main attention on the traffic [Dingus et al. 1988; Kun et al. 2009], this more passive mode, where the route is defined by the system, limits acquiring knowledge about the surrounding environment [Held and Hein 1963]. On the other hand the standard device for pedestrians, maps offer a survey perspective of the surrounds and thereby enable wayfinders to improve their environmental knowledge and have the benefit of controlling the wayfinding process instead of completely externalizing it [Ishikawa et al. 2008; Thorndyke and Hayes-Roth 1982]. Such maps leave the route choices with the navigator. The question which kind of instructions wayfinders prefer is highly dependent on the particular context. While visiting a museum, navigating on one's own and a free, meandering exploration might be desired. In other large public buildings, like airports and administrative buildings, the common goal is to reach a target destination as quickly as possible. Here minimizing search for wayfinding information and decision-making is appreciated. Navigational devices allow people to augment and combine their internal cognitive information processing with perception and manipulation of an external information representation and thereby enable users to perform computational offloading [Scaife and Rogers 1996].

The contribution of this work is to provide a first insight on how much additional environmental and signage information navigators use when they are equipped with either a classical printed mobile map or a digital mobile map.

- First contribution: Understand how classical wayfinding devices support navigators and understand when they recurse to information beyond the one offered by the devices, such as environmental information.

- Second contribution: Contrast wayfinders' information search regarding navigation assistance based on the environmental features of decision points.

- Third contribution: Identify which characteristics of decision points and wayfinding devices lead to more straightforward, satisfying wayfinding and a lower search for visual information and less attention to irrelevant environmental features, like incorrect route options.

\section{Background}

Navigating to a destination is a natural act of everyday life and can be easy and rather automatized [Montello 2005]. For exam- 
ple finding one's way from the office to home. But such wayfinding tasks can also be difficult and require a lot of cognitive effort from the navigator. Wayfinding is the stage of planning and decision-making in navigation [Montello 2005] where navigators can draw inferences from the environment to form correct route choices. How difficult we find it to navigate from A to B depends in part on our familiarity with the surrounds [Gärling et al. 1983; Hölscher et al. 2006a], but also on the environments complexity and intelligibility. Research in environmental psychology indicates that pedestrians are able to identify the correct route choice at intersections by looking at photographs [Emo 2012] or judge a building's function by looking at its façade [Nasar et al. 2005]. But still almost everyone can tell a story of how they once got lost, even now where navigation assistance is omnipresent. The question this article tries to shed light on, is what helps people decide for a route, and which characteristics of decision points and wayfinding assistance do actually support navigators in taking the correct decision.

Several research approaches have tried to overcome the problems arising from map-based navigation, such as the visual attention switches that are necessary in order to obtain the information provided by the map, directing the attention away from the surrounding environment, disambiguation problems that are related to the matching process of the retrieved information to the environment and also focusing on hands-free solutions for navigation. Scholars have [Pfeiffer et al. 2015] introduced an actuated navigation approach, applying electrical muscle stimulation in order to steer the wayfinders through the environment. GazeNav [Giannopoulos et al. 2015] is a gazebased pedestrian navigation approach informing wayfinders through vibro-tactile feedback whenever they are gazing at the street they have to follow. There are also several other vibrotactile feedback approaches that are based on a belt [Van Erp et al. 2005] or even a shoe-based [Schirmer et al. 2015] directional vibration method, providing the rough direction to follow. Although these approaches are very interesting and provide novel solutions to the mentioned problems, they eliminate the use of a map. This can have an impact on spatial knowledge acquisition, especially survey knowledge. Moreover, they exclude the wayfinder from the navigation process. Wayfinder don't have to make any spatial decisions, they only follow a systems feedback. This can result in a patronizing effect, which might not be desired and accepted by wayfinders. In our work instead of eliminating the map usage, we aim at optimizing it by adapting the type of instructions given to the user, thus, reducing the time necessary to interact with the map in order to be able to make a wayfinding decision.

A review of mobile HCI research methods noted that the current focus lies on building systems, and less on understanding design and usage [Kjeldskov and Graham 2003]. And also other researchers emphasized the importance of focusing on the context of usage when evaluating interactions with mobile systems [Li and Willis 2006], because in contrast to desktop-based interactions, users are faced with moving in space and therefore changing surrounds. Beyond the characteristics of the navigational device, wayfinding is also shaped by architectural properties. Werner and Long [2003] have looked at the usability of buildings and stated that architectural design can have multiple representational, aesthetical, and emotional, but also functional purposes. Also other scholars defined the ease of wayfinding as an essential function of a building's design, and even formed the analogy of space as a machine [Corbusier 1931; Passini 1984]. In indoor environments successful navigation can be impeded by missing signage, restricted visual access, minimal architectural differentiation, and complex plan configuration [Weisman 1981]. Several studies have shown that spatial configuration has an impact on wayfinding behavior [Haq and Zimring 2003; Hölscher et al. 2012; Peponis et al. 1990].

The concept of affordances has extensively been used in human computer interaction (HCI) and other psychological fields [Norman 2013]. Originally it was introduced by Gibson, investigating how people perceive their environment, extract information from a stimulus and deduce possible actions [Gibson 1979]. A lot of previous research has focused on "knowledge in the head" [Norman 2002], the presentations that people form of their surrounds. But it seems equally important to focus on "knowledge in the world", that knowledge is distributed and can be intrinsic to the wayfinder or be residing in the world [Montello 2007; Raubal and Worboys 1999]. Such "knowledge in the world" can reside in navigational devices, as well as the environment. Navigators' goal-driven reasoning starts with incomplete and imprecise knowledge derived from imperfect observations of space [Raubal and Worboys 1999]. The environment's affordances can influence the usefulness of a navigational device and vice versa [Baus et al. 2005]. Such devices can convey additional information and act as a mediator between environment and navigator, but are not properties of a building as such [Gärling and Golledge 1993; Werner and Long 2003]. Scholars have tried to classify different kinds of areas navigators are confronted with during navigation, some of them offering different options and holding the necessity to form a decision. Lynch [Lynch 1960] distinguishes landmarks, nodes, paths and regions in a city. Here a node is a point with high navigational uncertainty where several directions can be taken. Other scholars call such areas decision scenes or decision points [Gaisbauer and Frank 2008]. Nodes are connected by paths that are unidirectional and therefore have a low uncertainty [Lynch 1960; May et al. 2003]

In this paper we address navigators' decision-making at indoor decision points from a usability perspective. A decision point is defined as a location where navigators are faced with more than one possible option to go further, and their navigational uncertainty requires attention. Such decision points can either directly follow each other, or they can be connected via longer paths that don't require any decision-making and therefore lower attention, but allow the navigator to perform other actions, like storing and recalling environmental information and planning the route ahead. Different presentation modes of navigation devices elicit different kinds of knowledge, and also have different benefits when it comes to wayfinding efficiency. Simple turn-by-turn instructions, like those provided by signs or in-car navigation assistances, only give information about the current decisionsituation, and therefore only allow navigators to acquire landmark- or route-knowledge. Map-like overview presentations that show the relations between different decision-points enable survey-knowledge, and thus a more elaborate representation of the surrounds [Ishikawa et al. 2008; Thorndyke and Hayes-Roth 1982]. While turn-by-turn instructions don't require any decision from navigators, overview representations might confront them with several options, but also allow for obtaining a better understanding of the environment. Depending on the complexity of the current situation, navigators might prefer one presentation format over the other. In analogy to navigation through the information architecture of websites, this experiment focuses on evaluating decision points navigators are faced with within buildings. But beyond merely looking at architectural characteristics of decision points, also aiming to shed light on the role of navigation devices. Observing navigators visual fixations can 
reveal significant insights [Giannopoulos et al. 2013], especially regarding their usage of environmental and navigational device information, and the interplay of both. We aim to thereby get a more holistic view on peoples' attentional and behavioral patterns while navigating indoor environments using digital navigation devices.

Previous studies have clustered pedestrians according to their goals or focused on wayfinding support design based on cognitive or visual abilities [Jain et al. 2013; Rassmus-Gröhn and Magnusson 2014; Wen et al. 2013]. Our target is to identify how environmental characteristics provide information that shapes navigators' decisions. Furthermore we hope to illuminate how wayfinding devices can moderate, even improve, navigational choices and support efficient wayfinding. We focus on the interplay of the user, the wayfinding device as well as the environment, because we believe that looking at those entities in isolation does not sum up to what scrutinizing all three together can reveal. To be able to develop data-driven recommendations for future design we start at the fundamental level and do not compare different design options or visualization techniques, but look at the interplay of navigation devices with navigators' visual information search at various decision points.

\section{Method}

60 participants ( 30 male), between 18 and 78 years old $(M=36.8$, $S D=18.9$ ) individually navigated to three destinations in the same order. The participants were randomly assigned to navigate with either: 1$)$ a customary printed map $(n=20), 2)$ a digital map on a smartphone $(n=20)$, or 3 ) no map (i.e., using only the building and its signage for orientation; $n=20$ ). Due to the possible effect of age, individual spatial abilities and educational background on the outcome variables the sample had to go beyond a student sample. Participants were recruited via an advertisement in a local newspaper and reimbursed with 30 \$ per hour. All participants were unfamiliar with the building the testing took place in. Furthermore they all had no motor impairments in their hands/arms, were able to walk up stairs, and had normal or corrected-to-normal vision. When two raters agreed that eye-tracking quality was unsatisfying, the participant was taken out of the analysis. The final dataset included 13 participants in the first condition (No Map), 11 participants in the second condition (Paper Map), and 13 participants in the third condition (Digital Map).

\subsection{Experimental design}

We used a between-subject experimental design using navigation device (signage, printed map, digital map) as an independent variable and fixation frequency on map, signage, the correct route option and incorrect route options as dependent measures.

\subsection{Procedure}

Participants were individually tested in a session, where each participant was asked to individually search for three destinations (rooms in the building) in the same fixed order. Navigators' wayfinding behavior and gaze was captured with mobile eyetracking technology (SensoMotoricInstruments ETG 2, binocular mobile eye tracker). A researcher followed each of the navigators to tell them their new goal destination once they had arrived at a goal, and to give corrective feedback if they deviated from the shortest path at decision points. The ideal path (shortest path connecting start and goal location) was defined beforehand. When navigators decided to take an incorrect path, the researcher gave a short feedback and asked the participant to follow the correct option. There were three points in the building were two options were equally effective and could therefore both be counted as a correct path choice (see Figure 1), and those decision points were taken out of the analysis.

\subsubsection{The building}

The testing took place in a large university office building $\left(56^{\prime} 000 \mathrm{~m}^{2}\right.$ ), with 700-750 rooms, eight incongruent floors and disorienting staircases. In many places visual access is restricted, architectural differentiation is minimal, and the plan configuration is complex - all of which impedes successful navigation

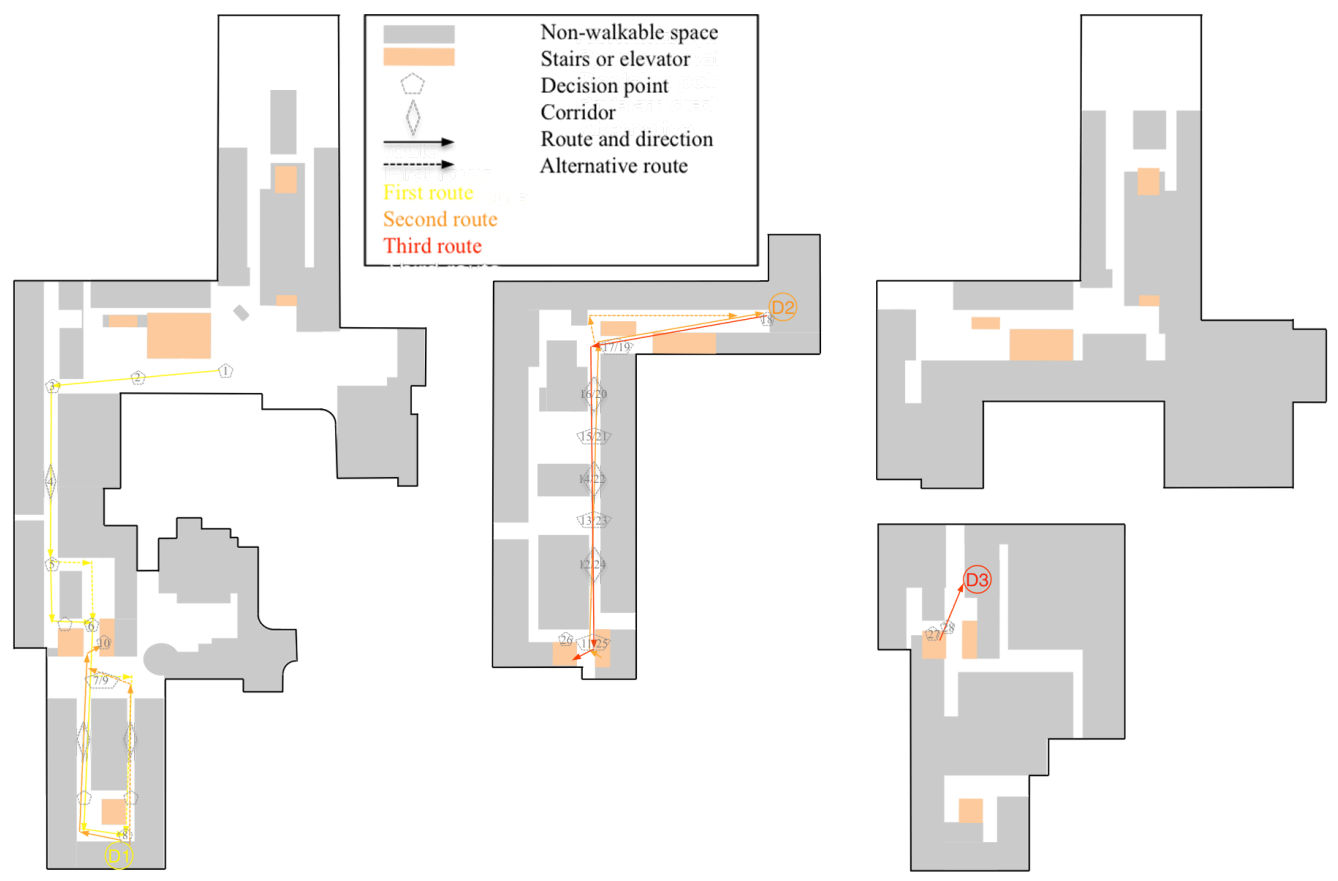

Figure 1: The three destinations and connecting routes, and decision points. 
[Weisman 1981]. The building has stringent building-wide signage and is prototypical of an office building, which people usually only enter to go to specific rooms.

\subsubsection{Signage}

The full-coverage numerical signage gives navigators very precise and reliable direction information. The first letter indicates the floor (from $\mathrm{A}$ to $\mathrm{H}$ ), the following numbers are equivalent on all floors and thereby represent a vertical vector through the building. Those numbers also successively increase and decrease and thereby allow navigators to draw inferences not only on the floor, but also on the direction where a room is located.

\subsubsection{Maps}

Paper maps were printed on $200 \mathrm{~mm}$ x $190 \mathrm{~mm}$ of laminated paper with a spiral binding. The digital maps were presented on a Samsung Galaxy Note II with a screen size of 6.85 x 12.18 $\mathrm{mm}$, and a diagonal of $139.7 \mathrm{~mm}$. The phone's screen size fits current smartphone standards, like the iPhone 6 Plus with a screen diagonal of $139.4 \mathrm{~mm}$. Paper and digital maps had the same layout and provided the same information (based on the Google Maps display for Android [Google Inc. 2013]). The digital maps allow the user to zoom into the map to focus on specific points within the floorplan or to zoom out to get an overview of the environment. Each floor can individually be selected by clicking on the respective number on a vertically presented list (A to $\mathrm{H}$ ). Furthermore the digital map allows for rotating it, so navigators have the option to align it according to their own heading. The digital maps included a blue dot symbolizing the current position of the navigators. Because this dot had a rather high variability and high error rate, wayfinders largely ignored it.

\subsubsection{Destinations}

The destinations were three office rooms with a room number that were located on different floors in different parts of the building. Like the start point, the first destination was on the ground floor. To reach the second destination on the 4th floor participants had to use an elevator, to reach the third destination on the -1 floor, they had to take stairs (see Figure 1).

\subsubsection{Decision points}

Each area that offered several route options was identified. Overall navigators were each faced with 28 decision points; 6 on the first route, 7 on the second route, and 8 on the third route. Because the third route partly covered the same path as the second route, 4 out of the 7 decision points were seen twice by the participant, but from a different direction (see Figure 1). As soon as the navigator had stepped through the doorframe of the correct route option a new segment started. When people then entered a corridor, those were treated as individual segments of the analysis. The corridor segment extended from the doorframe until the next route options became visible. There were 7 corridors taken into account for the analysis, furthermore we categorized the 21 remaining decision points into $t$-junctions, turnoffs, and areas where floor changes are possible (via stairs or lift).

\subsubsection{Areas of Interest}

To achieve a more fine-grained analysis of the visual attention patterns of the navigators, their gaze was analyzed. It was captured and counted whenever they fixated an area of interest (AOI). Fixation detection was conducted with the standard algorithm of the SMI software package BeGaze. To understand wayfinding device usage the fixations on signage and maps was captured. Furthermore the fixations on the correct route option as well as the incorrect route options were counted.

\section{$4 \quad$ Results}

We first report the results examining the relationship between navigation device condition and the fixation patterns for the individual decision points. To condense the findings, we later go beyond individual segments, and categorize the individual decision points like mentioned in 3.2.5. We conducted four mixedfactor ANOVAs, treating fixations at decision points as repeated-measures allowed to take within-subject variance into account. The independent variable was the navigation device navigators used.

\subsection{Effect of navigation device on fixation fre- quencies at decision points}

Participants walked a route that was divided into 28 segments; they either navigated with the signage, a paper map, or a digital map. We captured their fixation frequencies. Analyses aimed to compare the effect of navigation device (No Map, Paper Map, Digital Map) on fixation frequency (signage, the correct route option, and the incorrect route option) and a two-way, 3 (condition, between-subjects) x $28_{\text {(decision points within subjects) }}$ MANOVA was conducted. Mauchly's test was conducted which revealed that the assumption of sphericity had been violated for signage $\left(\chi_{(377)}^{2}=\right.$ $1632.21, p=.00)$, and the correct route option $\left(\chi_{(377)}^{2}=952.13\right.$, $p=.00)$. To address this violation a Greenhouse Geisser cor-

Table 1: Results of two-way 3x28 MANOVA and 2x28 ANOVA, comparing effect of decision point and navigation device on the fixation frequency on signage, the correct route choice, and incorrect route choices.

\begin{tabular}{|c|c|c|c|c|c|c|c|c|c|c|c|}
\hline & \multicolumn{4}{|c|}{$\begin{array}{c}\text { Decision Point Influence } \\
\text { (Tests of Within-Subjects Effects) }\end{array}$} & & \multicolumn{5}{|c|}{$\begin{array}{c}\text { Navigation Device Influence } \\
\text { (Tests of Between-Subjects Effects) }\end{array}$} & \\
\hline & AOIs: Fixations on: & $\mathrm{F}$ & $\mathrm{df}$ & Sig. & & & AOIs: Fixations on: & $\mathrm{F}$ & df & Sig. & \\
\hline Decision points & Map & 24.4 & 4.9 & .00 & ** & Intercept & Map & 165.1 & 1 & .00 & $* *$ \\
\hline Decision points $*$ & & & & & & Navigation & & & & & \\
\hline Navigation device & & 1.6 & 4.9 & .17 & & device & & 6.2 & 1 & .02 & $*$ \\
\hline \multicolumn{12}{|l|}{ Error } \\
\hline (Decision points) & & & 82.8 & & & Error & & & 17 & & \\
\hline \multirow[t]{3}{*}{ Decision points } & Signage & 16.2 & 3.1 & .00 & $* *$ & Intercept & Signage & 145.4 & 1 & .00 & $* *$ \\
\hline & Correct route choice & 35.2 & 6.7 & .00 & $* *$ & & Correct route choice & 247.1 & 1 & .00 & $* *$ \\
\hline & Incorrect route choice & 23.0 & 2 & .00 & $* *$ & & Incorrect route choice & 132.7 & 1 & .00 & $* *$ \\
\hline Decision points * & Signage & 3.7 & 6.2 & .00 & $* *$ & Navigation & Signage & 20.3 & 2 & .00 & $* *$ \\
\hline \multirow[t]{2}{*}{ Navigation device } & Correct route choice & 3.3 & 13.4 & .00 & $* *$ & device & Correct route choice & 6.7 & 2 & .00 & $* *$ \\
\hline & Incorrect route choice & 6.4 & 4.0 & .00 & $* *$ & & Incorrect route choice & 19.7 & 2 & .00 & $* *$ \\
\hline Error & Signage & & 86.8 & & & Error & Signage & & 28 & & \\
\hline (Decision points) & Correct route choice & & 187.6 & & & & Correct route choice & & 28 & & \\
\hline
\end{tabular}




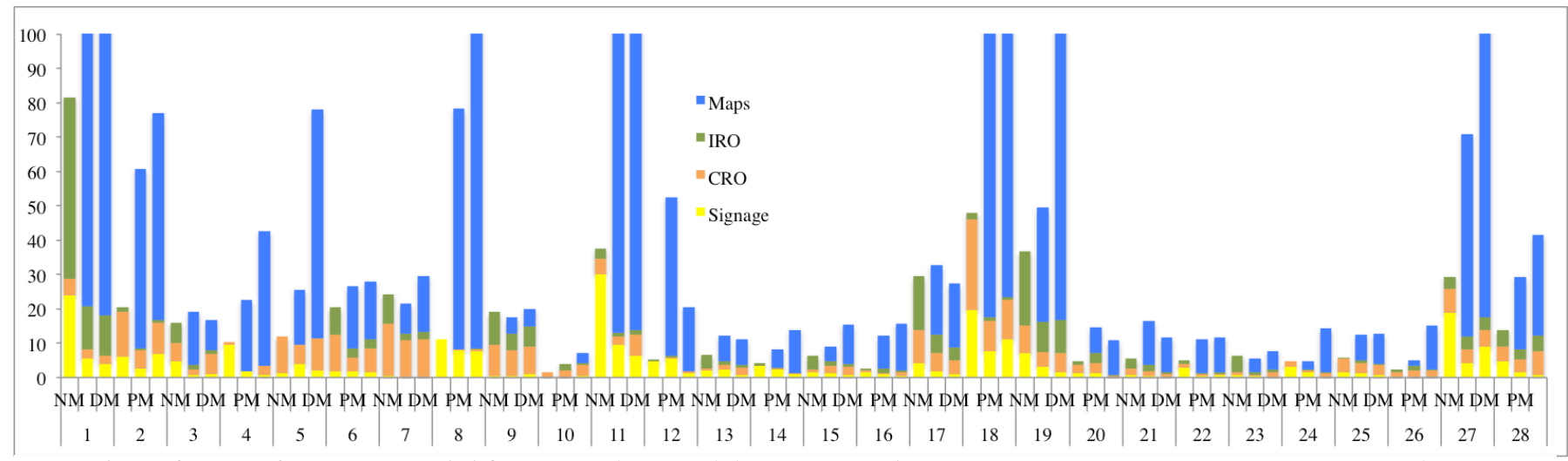

Figure 2: Mean fixations on each AOI, per condition and decision point. ${ }^{*} N M=$ No Nap; PM= Paper Map; DM = Digital Map

rection for degrees of freedom was applied $(\varepsilon=.12$ and $\varepsilon=.25)$.

Such a correction makes the test more conservative to avoid spuriously significant results. Mauchly's test could not be computed for the incorrect route option due to insufficient residual degrees of freedom. Because the assumption of sphericity has been violated in the other part dataset, we corrected the degrees of freedom using Greenhouse Geisser estimates of sphericity $(\varepsilon$ $=.07)$.

\subsubsection{Fixations on signage}

Results of the MANOVA indicated that fixation frequency did differ between the decision points regarding signage fixations $\left(\mathrm{F}_{(3.1,86.8)}=16.23, p=.00\right)$, and also between navigators using only signage, Digital Maps, or printed maps $\left(\mathrm{F}_{(2,28)}=20.31, p=\right.$ $.00)$. There was also a significant decision point $\mathrm{x}$ navigation device interaction for fixations on the signage $\left(\mathrm{F}_{(6.2 .86 .8)}=3.69, p\right.$ $=.00)$. These observations were confirmed by planned contrasts, which indicated that navigators only using signage did significantly differ from the ones using the Paper Map $\left(\mathrm{t}_{(2)}=5.0, p=\right.$ $.00)$, and the Digital Map group $\left(\mathrm{t}_{(2)}=5.7 p<.001\right)$, while the two map groups did not differ regarding the number of signage fixations (Figure 2). The No Map group had the most fixations on signage and signage fixations showed large differences between the different decision points (see Table 1).

\subsubsection{Fixations on the correct route option}

Fixations differed between decision point types regarding fixations on the correct route option $\left(\mathrm{F}_{(6.7,187.6)}=35.25, p<.001\right)$. Here fixation frequency differences were lower between the different navigation devices than between the different decision points $\left(\mathrm{F}_{(2,28)}=6.72, p<.001\right)$. There was also a significant decision point $\mathrm{x}$ navigation device interaction for fixations on the correct route option $\left(\mathrm{F}_{(13.3,187.6)}=3.85, p=.00\right)$, indicating higher fixation frequency for some decision points depending on the used navigation device (Table 1). These observations were confirmed by planned contrasts, which indicated that the No Map group did significantly differ from the Paper Map group $\left(\mathrm{t}_{(2)}=3.66, p<.001\right)$ and the Digital Map group $\left(\mathrm{t}_{(2)}=1.8, p=\right.$ n.s..). Again the two map groups did not significantly differ from each other $\left(\mathrm{t}_{(2)}=1.6, p=n . s\right.$.). The No Map group had the most fixations on the correct route option; furthermore the decision points differed in the number of fixations for all groups (Figure 2).

\subsubsection{Fixations on the incorrect route option}

For the incorrect route options the fixation frequencies significantly differed depending on whether navigators used signage alone, the Digital Map, or Paper Map $\left(\mathrm{F}_{(2,32)}=19.73, p<.001\right)$ and the fixations frequency also differed between different decision points $\left(\mathrm{F}_{(2,56)}=22.98, p<.001\right)$. Furthermore there was a significant decision point $\mathrm{x}$ navigation device interaction $\left(\mathrm{F}_{(4.56)}=6.39, p<.001\right)$. Planned contrasts could substantiate this pattern, while the No Map group significantly differed from the Paper Map $\left(\mathrm{t}_{(2)}=5.2, p<.001\right)$ and Digital Map group $\left(\mathrm{t}_{(2)}=\right.$ $5.5, p<.001)$, the two map groups did not significantly differ from each other $\left(\mathrm{t}_{(2)}=.4, p=n . s\right.$.). This replicates the finding described before, the No Map group has the most fixations, and the map groups do not differ from each other, while the decision points do substantially differ in the fixation frequency over all navigation devices (Figure $2 \&$ Table 1 ).

\subsubsection{Fixations on the map}

We compared the effect of map type (digital, printed) on fixations on the map over all decision points. Therefore we conduct-

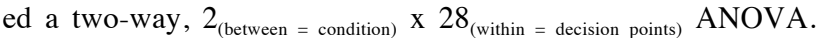
Multivariate tests and the Mauchly's test could not be computed due to insufficient residual degrees of freedom. Because the assumption of sphericity has been violated in the other analyses, degrees of freedom were corrected using Greenhouse Geisser correction $(\varepsilon=.18)$. The results indicate a significant difference between the map conditions on the number of map fixations $\left(\mathrm{F}_{(1,17)}=6.18, p<.05\right)$, and differences were even higher between the decision points $\left(\mathrm{F}_{(14.9 .82 .8)}=24.45, p<.001\right)$. Furthermore there was no significant decision point $\mathrm{x}$ navigation device interaction $\left(\mathrm{F}_{(4.9,82.8)}=1.6, p=\right.$ n.s. 2$)$.

Table 2: Results of the 2x4 MANOVA and 1x4 ANOVA comparing effect of navigation device on fixation frequency on signage, the correct route choice, incorrect route choices, and maps over decision point types. ${ }^{*} R O=$ route option

\begin{tabular}{|c|c|c|c|c|c|c|c|c|c|c|c|c|c|c|c|}
\hline & \multicolumn{4}{|c|}{$\begin{array}{l}\text { Decision Point Influence } \\
\text { (Within Subjects Effect) }\end{array}$} & & \multicolumn{4}{|c|}{$\begin{array}{c}\text { Navigation Device * Decision Point } \\
\text { (Interaction) }\end{array}$} & & \multicolumn{5}{|c|}{$\begin{array}{c}\text { Navigation Device Influence } \\
\text { (Between Subjects Effect) }\end{array}$} \\
\hline & $\mathrm{F}$ & $\mathrm{df}$ & err df & $\mathrm{p}$ & & $\mathrm{F}$ & $\mathrm{df}$ & err df & $\mathrm{p}$ & & $\mathrm{F}$ & $\mathrm{df}$ & err df & $\mathrm{p}$ & \\
\hline Signs & 11.9 & 1.9 & 69.1 & .000 & $* *$ & 2.9 & 1.9 & 69.1 & .03 & $*$ & 2.4 & 2 & 35 & .1 & \\
\hline Correct RO & 43.9 & 2.2 & 45.8 & .000 & $* *$ & 4.3 & 2.2 & 45.8 & .01 & $* *$ & 12.5 & 2 & 35 & .000 & $* *$ \\
\hline Incorrect RO & 50.4 & 3 & 105 & .000 & $* *$ & 2.6 & 3 & 105 & .02 & $*$ & 3.3 & 2 & 35 & .05 & $*$ \\
\hline Map & 5.7 & 1.8 & 41.4 & .08 & & 1.2 & 1.8 & 41.4 & .3 & & 2.4 & 1 & 23 & .135 & \\
\hline
\end{tabular}




\subsection{Effect of navigation device on fixation pat- terns over decision points types}

To condense the analysis we decided to cluster the different decision points based on their features. 1) corridors, 2) $t$ junctions - navigators are only able to go left or right, 3) turnoffs - navigators can either go straight or take a turn to one side, and 4) floor changes - navigators are faced the option to switch the floor via lift or stairs [Passini 1984; O'Neill 1991]. To assess the effect of navigation device and the difference between the decision point types on fixation patterns we conducted a $3_{\text {(between }}=$

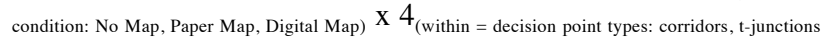
turnoffs, intersections) MANOVA with three dependent variables (fixation on signage, the correct route option, and the incorrect route options). Mauchly's test indicated that the assumption of sphericity had been violated and therefore degrees of freedom were corrected using Greenhouse Geisser correction for signage $\left(\chi_{(5)}^{2}=17,4, p<.05, \varepsilon=.77\right.$, and the correct route option $\left(\chi_{(5)}^{2}=28,2, p<.00, \varepsilon=.72\right)$. Such a correction makes the test more conservative to avoid spuriously significant results.

\subsubsection{Fixations on signage}

Results of these analyses indicated that fixations did differ between the decision point types regarding signage fixations $\left(\mathrm{F}_{(1.9,69.1)}=11.9, p<.001.\right)$. The number of fixations on signage did not significantly differed between the navigation device conditions $\left(\mathrm{F}_{(2,35)}=2.4, p=n . s\right.$. $)$. Planned contrasts revealed that the No Map group significantly differed from the two Map groups $\left(\mathrm{t}_{(2)}=2.1, p<.05\right)$, while the two Map groups did not differ from each other $\left(\mathrm{t}_{(2)}=.4, p<.05\right)$. The navigation device $\mathrm{x}$ decision point type interaction was also significant $\left(\mathrm{F}_{(1.9,69.1)}=\right.$ $2.79 p<.05$ ) (Table 2). There was an influence of decision point type and navigation device on the frequency of signage fixations. Signage was most frequently used at turnoffs and least at decision points that allowed for floor changes.

\subsubsection{Fixations on the correct route option}

Fixations differed between decision point types regarding fixations on the correct route option $\left(\mathrm{F}_{(222,45.8)}=43.9, p<.001.\right)$, Again fixation frequency differences were higher between the decision points than between navigation devices $\left(\mathrm{F}_{(2,35)}=12.5, p\right.$ $<.000$.). There was also a significant decision point $\mathrm{x}$ navigation device interaction for fixations on the correct route option $\left(\mathrm{F}_{(222,45.8)}=4.3, p<.01\right)$ indicating higher fixation frequency for some decision points depending on the navigation device condition (Table 2). Planned contrasts indicate that navigators without a map significantly differ from those using a map $\left(\mathrm{t}_{(2)}=5, p<\right.$

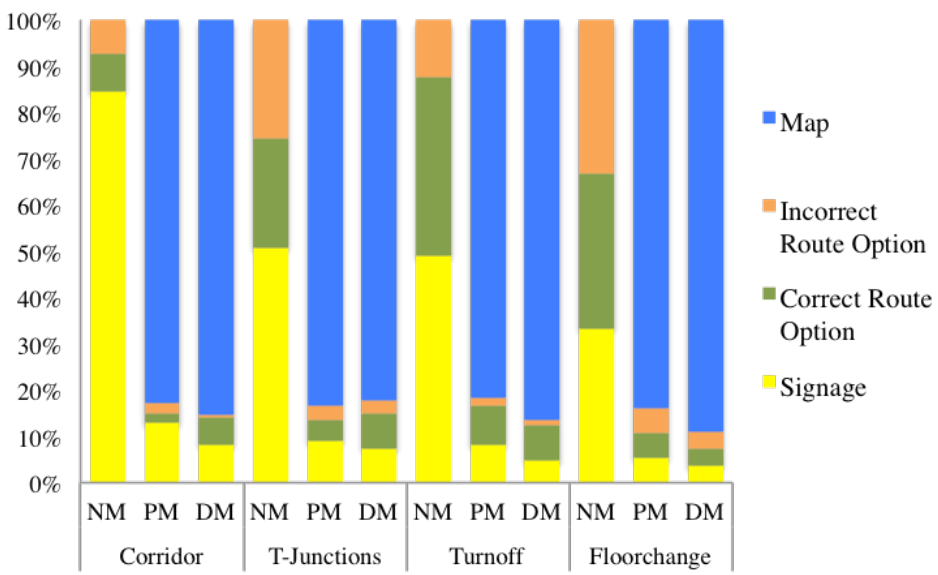

$.001)$. The two map types did not show a significant difference $\left(\mathrm{t}_{(2)}=.3, p=n . s\right.$.) (Table 2). Turnoffs led to a higher amount of fixations in all groups than the other decision point types, while corridors had the fewest. Navigators without a map differed from navigators in both Map groups, but the Map groups did not significantly differ from each other (Figure 3 ).

\subsubsection{Fixations on the incorrect route options}

Fixation frequency on the incorrect route options differed significantly between the decision point types $\left(\mathrm{F}_{(3,105)}=50.4, p<\right.$ $.001)$ and also between the navigation devices $\left(\mathrm{F}_{(2,35)}=3.3, p<\right.$ $.05)$. Furthermore there was a significant decision point $\mathrm{x}$ navigation device interaction for fixations on the incorrect route option $\left(\mathrm{F}_{(3,105)}=2.6, p<.01\right)$. Planned contrasts indicate that navigators without a map significantly differ from those using a Paper Map $\left(\mathrm{t}_{(2)}=3.2, p<.01\right.$.) and a Digital Map $\left(\mathrm{t}_{(2)}=1.8, p=\right.$ n.s.). The two map types did not show a significant difference $\left(\mathrm{t}_{(2)}=1.6, p=n . s\right.$.) (Table 2). While corridors had the least amount of fixations on the incorrect route option in all groups, tjunctions and turnoffs had more, and intersections again led to the most fixations in all groups (Figure 3).

\subsubsection{Fixations on the map}

We conducted a $2_{\text {(between }}=$ condition: Paper Map, Digital Map) $x 4_{\text {(within }}=$ decision point types: corridors, t-junctions, turnoffs, intersections) ANOVA with one dependent variable (fixation on the map). Mauchly's test indicated that the assumption of sphericity had been violated $\left(\chi_{(5)}^{2}=22.2, p<\right.$ $.001)$, therefore degrees of freedom were corrected using Greenhouse Geisser estimates of sphericity $(\varepsilon=.6)$. The results indicate that there was no significant difference between the map types on the number of map fixations $\left(\mathrm{F}_{(1.23)}=2.4 p=n . s.\right)$, nor between the decision point types $\left(\mathrm{F}_{(1.8,41.4)}=5.7, p=n . s\right.$. $)$. Furthermore there was no significant decision point $\mathrm{x}$ navigation device interaction $\left(\mathrm{F}_{(1.8,41.4)}=1.2, p=n . s\right.$.) (see Table 2). Paper map and Digital Map users did not significantly differ in the amount of map fixations; this result was consistent for each of the individual decision point types (Figure 3). The fewest map fixations happened while travelling through corridors, most fixations happened at turnoffss.

\section{Discussion}

In this study participants individually navigated to three destinations either without a map, with a Paper Map, or a Digital Map. They each were faced with 28 decision points. Their visual attentions pattern was captured and analyzed.

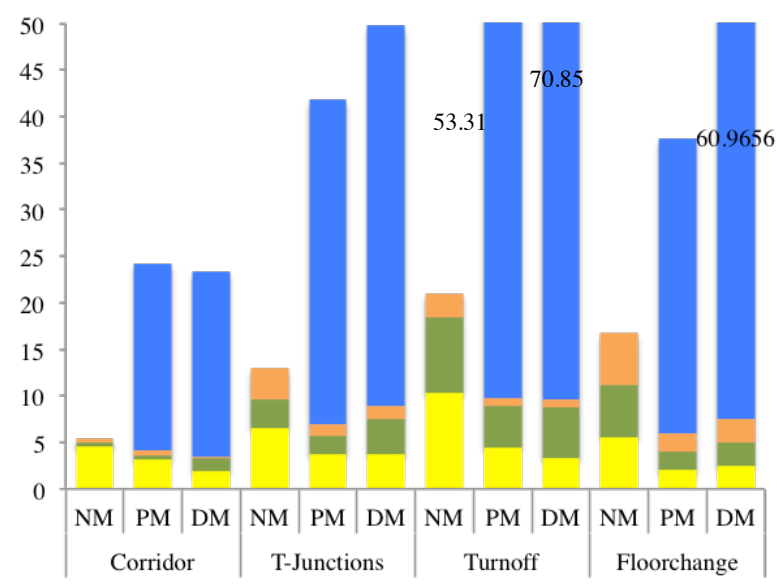

Figure 3: Mean fixations on each AOI, per navigation device and decision point type. On the left transferred into $100 \%$. $* N M=$ No Map; $P M=$ Paper Map; DM = Digital Map 


\subsection{Effect of navigation device on fixation pat- terns over decision points types}

The different decision points were clustered based on their features. 1) corridors, 2) $t$-junctions - navigators are only able to go left or right, 3) turnoffs - navigators can either go straight or take a turn to one side, and 4) floor changes - navigators are faced with the option to change the floor.

\subsubsection{Fixations on signage, the correct route op- tion and the incorrect route options}

Wayfinders that used a map (digital or printed) had fewer fixations on the signage than those who did not have access to a map. Furthermore there was an influence of the decision point types on the frequency of signage fixations. The two map types did not show any significant differences in their visual attention on signage (see Figure 2). A similar picture emerged for fixations on the correct route option. Here navigation device type did have an effect on fixation frequency, and fixations did differ regarding the different decision point types. Corridors led to much fewer fixations compared to the other decision point types. Navigators without a map differed from navigators in both map groups, but the map groups did not significantly differ from each other (see Figure 2). Similarly for the visual attention on the incorrect route option, the fixation frequency did differ between the groups, and between the decision points. While corridors had the least amount of fixations on the incorrect route option in all groups, t-junctions and turnoffs had more, and floor changes again led to the most fixations in all groups (see 3).

\subsubsection{Fixations on the map}

Mobile map users showed as many fixations on the map than the ones using a printed version for each of the decision point types. From all AOIs maps were the ones were most of the visual attention was focused on, which indicate that a high amount of their attention was paid to the device. Potentially this division of attention was not only caused by the presentation format of the map, but by the potential interactions with the device. For both map types least fixations on the map happened while travelling through corridors, the most fixations happened at turnoffs. This finding suggests that travelling along a corridor requires less attention and processing, and that the required cognitive effort increases with the number of possible route options.

When it comes to the deductive theory-driven categorization of the decision points into corridors, $t$-junctions, turnoffs, and floor changes, one could argue that it is too arbitrary, although based on previous research. It might be an interesting insight if further analyses would be based on a data-driven categorisation by clustering decision points based on gaze data, sheding light on similarities in visual attention and information seacrch patterns.

\subsection{Effect of navigation device on fixation pat- terns over decision points}

\subsubsection{Fixations on signage, the correct route op- tion and the incorrect route options}

The 28 different decision points largely varied regarding their numbers of fixations. Signage fixations revealed substantial differences between the decision points regarding the attention paid to signage, the No Map group had the most fixations on signage. The correct route option had most fixations from the No Map group and the decision points differed in the number of fixations for all groups. For the incorrect route options, the fixation pattern repeats the ones described before, the No Map group has the most fixations, and the map groups do not differ from each other, however the decision points do substantially differ in the fixation frequency over all navigation device conditions. Looking at the fixation frequencies, it becomes very obvious that map users (of both types) mostly fixate the map and much less on the environment or the signage (see Figure 2). The No Map group on the other hand had more fixations on those environmental elements than the map groups. Future analyses could normalize the fixations for each decision point by dividing the number of all fixations by the time spend on the decision point. We decided against such normalization, because more complex decision points might lead to navigators spending more time on decision making, and therefore being slower to move on and to fixate more, which is relevant information that would be taken out of the data with normalizing.

\subsubsection{Fixations on the map}

The analysis for the individual decision point indicated a slightly different pattern than the analysis of the decision point categories. Digital map users had significantly more fixations on the map than Paper Map users. Furthermore the number of fixations significantly differed between the decision points over the two conditions (Figure 2).

Although the authors had not predicted such a finding, the analysis revealed an interesting pattern regarding the amount of fixations at the starting points of each of the three destinations. Each of those starting points (decision point 1, 8, 18) shows much higher fixations on all areas of interest in all groups. This is in line with observations by [Downs \& Stea, 1973; Hölscher et al., 2006] who claim that at this point of the navigation process wayfinders orient themselves in the environment, identify their goal destination and choose the route ahead as much as possible, while later they might primarily be involved in updating their current location and monitoring the route and cognizing that the destination has been reached.

\subsection{Conclusions}

One main goal of this study was to shed light on which characteristics of decision points and wayfinding devices lead to a lower search for visual information and less attention to irrelevant environmental features, like incorrect route options. Furthermore this paper aimed to identify data driven recommendations for designing effective and satisfying wayfinding assistances. We can address this goal from two perspectives. First of all it became obvious that navigators have the highest amount of fixations on each kind of information - the environment, as well as maps and signage - when they are initially planning their route. Another interesting finding is that decision points along the route that would allow for a floor change again lead to a higher attention on visual information (decision points 11, 19, 27 ). One approach would therefore be to offer navigators a survey view of the surrounds while at the start point and to then offer them a different wayfinding assistance during the rest of the route that carries less information and offers more of a reassurance function as well as local turn-by-turn directions. This is in line with other recently published research findings regarding pedestrian navigation support [Giannopoulos et al. 2015; Pfeiffer et al. 2015]. Designing satisfying feedback at those decision points that allow for a floor change, is a challenge for future design. The device could either also reassure wayfinders that they are still on the correct route and give them simple route instructions. Alternatively at such points wayfinding assistance could give travelers the option to apply one of three strategies; 
1) change the floor now and then go further, 2) go into the right direction until the final floor change, or 3) change the floor at a central point [Hölscher et al. 2006b]. Such design choices could be inspired by the study at hand and following studies systematically varying the characteristics of decision points. Future analysis could go into further depth by taking into account fixation durations, as well as saccadic movements including scanpath information to provide a more fine-grained and processedbased picture of the data.

\section{Acknowledgements}

We would like to thank Carina Hoppenz for her support with the data collection and eye tracking analysis.

\section{References}

Baus, J., CheVerst, K., AND Kray, C. 2005. A Survey of Mapbased Mobile Guides. In: P.D.L. Meng, D.T. Reichenbacher and P.D.A.Zipf, eds., Map-based Mobile Services. Springer Berlin Heidelberg, 193-209.

CORBUSIER, L. 1931. Towards a new architecture. Courier Dover Publications.

Dingus, T.A., Antin, J.P., Hulse, M.C., AND WieRwiLle, W. W. 1988. Human Factors Issues Associated with in-Car Navigation System Usage An Overview of Two in-Car Experimental Studies. Proceedings of the Human Factors and Ergonomics Society Annual Meeting 32, 19, $1448-1452$

Downs, R. AND STEA, D. 1973. Cognitive representations. Image and Environment, Chicago: Aldine (79-86).

Emo, B. 2012. Wayfinding in Real Cities: Experiments at Street Corners. In: C. Stachniss, K. Schill and D. Uttal, eds., Spatial Cognition VIII. Springer Berlin Heidelberg, 461-477.

VAn ERP, J.B., VAN Veen, H.A., Jansen, C., AND DobBins, T. 2005. Waypoint navigation with a vibrotactile waist belt. ACM Transactions on Applied Perception (TAP) $2,2,106-117$.

GAISBAUER, C. AND FrAnK, A.U. 2008. Wayfinding model for pedestrian navigation. AGILE 2008 ConferenceTaking Geo-information Science One Step Further, University of Girona, Spain.

GÄRLING, T. AND Golledge, R.G. 1993. Chapter 1 Understanding Behavior and Environment: A Joint Challenge to Psychology and Geography. In: Tommy Gärling and Reginald G. Golledge, ed., Advances in Psychology. North-Holland, 1-15.

GÄRLING, T., LINDBERG, E., AND MÄNTYLÄ, T. 1983. Orientation in buildings: Effects of familiarity, visual access, and orientation aids. Journal of Applied Psychology 68, 1, 177-186.
Giannopoulos, I., KiEFER, P., AND Raubal, M. 2013. The influence of gaze history visualization on map interaction sequences and cognitive maps. ACM Press, 1-6.

GiAnNOPOUlOS, I., Kiefer, P., AND RAUbAL, M. 2015. GazeNav: Gaze-Based Pedestrian Navigation. Proceedings of the 17th International Conference on Human-Computer Interaction with Mobile Devices and Services, ACM, $337-346$.

GIBSON, J.J. 1979. The ecological approach to visual perception. Boston, MA: Houghton Mifflin.

Google InC. 2013. Google Maps Mobile. Google Inc., Mountain View, CA, USA.

HaQ, S. And Zimring, C. 2003. Just Down The Road A Piece The Development of Topological Knowledge of Building Layouts. Environment and behavior 35, 1, 132-160.

Held, R. AND HEIN, A. 1963. Movement-produced stimulation in the development of visually guided behavior. Journal of comparative and physiological psychology 56, 5 , 872.

HÖLSCHER, C., BRÖSAMLE, M., AND VRACHLIOTIS, G. 2012. Challenges in multilevel wayfinding: A case study with the space syntax technique. Environment and Planning B: Planning and Design 39, 1, 63-82.

Hölscher, C., MeIlinger, T., VRaChliotis, G., ET AL. 2006a. The floor strategy: Wayfinding cognition in a multilevel building. Proceedings of the 5th International Space Syntax Symposium, 823-824.

Hölscher, C., Meilinger, T., Vrachliotis, G., Brösamle, M., AND KNAUFF, M. 2006b. Up the down staircase: Wayfinding strategies in multi-level buildings. Journal of Environmental Psychology 26, 4, 284-299.

ISHIKAWA, T., FuJIWARA, H., IMAI, O., AND OKABE, A. 2008. Wayfinding with a GPS-based mobile navigation system: A comparison with maps and direct experience. Journal of Environmental Psychology 28, 1, 74-82.

ISHIKAWA, T. AND MonTELLO, D.R. 2006. Spatial knowledge acquisition from direct experience in the environment: Individual differences in the development of metric knowledge and the integration of separately learned places. Cognitive psychology 52, 2, 93-129.

JAIn, D., JAIn, A., PAUl, R., KomarikA, A., AND BALAKRISHNAN, M. 2013. A path-guided audio based indoor navigation system for persons with visual impairment. ACM, 33 .

KJELDSKOV, J. AND GRAHAM, C. 2003. A review of mobile HCI research methods. In: Human-computer interaction with mobile devices and services. Springer, 317-335.

Kun, A.L., Paek, T., Medenica, Ž., Memarović, N., AND PALINKO, O. 2009. Glancing at personal navigation 
devices can affect driving: experimental results and design implications. Proceedings of the 1st International Conference on Automotive User Interfaces and Interactive Vehicular Applications, ACM, 129-136.

LI, C. AND WILLIS, K. 2006. Modeling Context Aware Interaction for Wayfinding Using Mobile Devices. Proceedings of the 8th Conference on Human-computer Interaction with Mobile Devices and Services, ACM, 97100 .

LYNCH, K. 1960. The image of the city. MIT press.

May, A., Ross, T., BAyer, S., And Tarkiainen, M. 2003. Pedestrian navigation aids: information requirements and design implications. Personal and Ubiquitous Computing 7, 6, 331-338.

Montello, D.R. 2005. Navigation. In: P. Shah and A. Miyake, eds., The Cambridge Handbook of visuospatial thinking. Cambridge University Press, New York, 257-294.

MONTELLO, D.R. 2007. The contribution of space syntax to a comprehensive theory of environmental psychology. Proceedings of the 6th International Space Syntax Symposium,_Istanbul, iv-1-12.Retrieved from http://www. spacesyntaxistanbul. itu.edu. tr/papers/invitedpapers/daniel_montello.pdf.

NASAR, J.L., STAMPS, A.E., AND HANYU, K. 2005. Form and function in public buildings. Journal of environmental psychology 25, 2, 159-165.

NORMAN, D.A. 2002. The design of everyday things. Basic books.

NoRman, D.A. 2013. Affordances, Conventions and Design (Part 2). Don Norman's jnd.org website / human centered design. http://jnd.org/dn.mss/affordance_conventions_and_des ign_part_2.html.

O’NeILl, M.J. 1991. Effects of signage and floor plan configuration on wayfinding accuracy. Environment and Behavior $23,5,553-574$.

PASSINI, R. 1984. Spatial representations, a wayfinding perspective. Journal of Environmental Psychology 4, 2, 153164.

PePonis, J., Zimring, C., AND ChOI, Y.K. 1990. Finding the Building in Wayfinding. Environment and Behavior $22,5,555-590$

Pfeiffer, M., Dünte, T., SchneEgass, S., Alt, F., And Rohs, M. 2015. Cruise Control for Pedestrians: Controlling Walking Direction using Electrical Muscle Stimulation. Proc. of CHI'15 (to appear).

RASSMUS-GRÖHN, K. AND MAGNUSSON, C. 2014. Finding the way home: supporting wayfinding for older users with memory problems. ACM, 247-255.
RAUBAL, M. AND WORBOYS, M. 1999. A formal model of the process of wayfinding in built environments. Spatial information theory. Cognitive and computational foundations of geographic information science, 748 748

SCAIFE, M. AND Rogers, Y. 1996. External cognition: how do graphical representations work? International Journal of Human-Computer Studies 45, 2, 185-213.

SChirmer, M., HARTMAnn, J., Bertel, S., AND Echtler, F. 2015. Shoe me the Way: A Shoe-Based Tactile Interface for Eyes-Free Urban Navigation. Proceedings of the 17th International Conference on HumanComputer Interaction with Mobile Devices and Services, ACM, 327-336.

SCHNITZLER, V. AND HöLSCHER, C. 2015. User experience and strategy choices during navigation: A content analysis of navigators using different types of wayfinding devices. .

SiegEL, A.W . AND WhITE, S.H. 1975. The development of spatial representations of large-scale environments. Advances in child development and behavior 10,9-55.

THORNDYKe, P.W. AND HAYES-Roth, B. 1982. Differences in spatial knowledge acquired from maps and navigation. Cognitive psychology 14, 4, 560-589.

WEISMAN, J. 1981. Evaluating architectural legibility wayfinding in the built environment. Environment and Behavior 13, 2, 189-204.

Wen, J., Helton, W.S., AND BillinghuRSt, M. 2013. Classifying users of mobile pedestrian navigation tools. ACM, $13-16$.

WeRnER, S. AND LONG, P. 2003. Cognition meets Le Corbusier-Cognitive principles of architectural design. In: Spatial cognition III. Springer, 112-126. 